of one or both eyes should start with an immediate intravenous injection of dexamethasone $10 \mathrm{mg}$ and then, as in a cardiac disaster, the patient should be rushed to hospital for admission, if possible to an intensive care ward. The cause of the blindness is likely to be an underlying medical condition and it is best to proceed without delay to treat the patient. Dexamethasone should be continued $4 \mathrm{mg}$ intramuscularly every six hours for three days. Prednisolone $20 \mathrm{mg}$ three times daily should be started on the first day and continued as described in your leading article."

I have not, moreoever, recommended temporal artery biopsy in view of the very precarious circulatory balance which may exis in giant cell arteritis between the internal and external carotid circulation. Temporal artery biopsy has disturbed this balance and produced ipsilateral blindness.

\section{GeRald Parsons-Smith}

Redhill, Surrey RH1 4QX

12 Parsons-Smith, B G, in Medical Ophthalmology, ed 1976.

\section{One-visit endoscopic clinic}

SIR,-I was interested to read the paper entitled "Evaluation of one-visit endoscopic clinic for patients with dyspepsia" by Dr A K Beavis and others (26 May, p 1387). This will be a lesson to those who use heavy sedationup to $50 \mathrm{mg}$ of diazepam for such a tolerable procedure.

We undertake on average 20-25 endoscopies a week and most cases are referred directly to the endoscopy unit as day cases. Ninety-five per cent of the patients have no premedication or sedation during the procedure. Full cooperation of the patients is achieved by explanation of the procedure to them by the referring doctor and the endoscopist. It seems that Dr Beavis and his colleagues have achieved such a high success rate (187 out of 200 patients) by having developed a rapport with the patients at the time of their detailed examination. I would agree with them that men and older patients tolerate the procedure well but I find that women, particularly under the age of 30 , are reluctant. It is interesting that $81 \%$ of their patients preferred barium meal examination and only $8 \%$ preferred endoscopy. $\mathrm{Up}$ to two-thirds of our patients prefer endoscopy after realising the value of direct visualisation.

I hope that the barium meal examination in each patient was performed for the purposes of their paper and that it is not a routine practice for each patient to have both endoscopy and a barium meal; otherwise this would invalidate cost-effectiveness and patient convenience.

\section{A N Chatterji}

University Department of
Medicine,
Leicester Royal Infirmary,
Leicester LE2 7LX

\section{Cervical cytology reporting}

SIR,-I should like to comment on the correspondence on this subject by $\operatorname{Dr} R \mathrm{E} \mathrm{G}$ Sloan (19 May, p 1356) and Dr M J Sworn (2 June, $p$ 1489). It has been the concern of many pathologists throughout the country to devise a simple, rapid, and accurate assessment of the cell content of smears for purposes of quality assurance. We in this laboratory have successfully practised such cell scoring for the past 10 years, the screeners entering the relevant data in the research boxes 26-30 at the bottom of the national cytology request/ report form (HMR 101/5) while screening the smear or smears.

The average smear under the $22-50 \mathrm{~mm}$ coverslip, using a $\times 10$ eyepiece and $\times 10$ objective, is approximately 30 fields horizontally and 10 fields vertically, giving a total of around 300 fields. In box 26 the technician scores the total cell conten as $\mathrm{C}_{1}$ if over $10000, \mathrm{C}_{2}$ if over $20000, \mathrm{C}_{3}$ if over 30000 , and $C_{4}$ if over 40000 . In box 27 the number of endocervical cells is similarly scored, together with any metaplastic and transformation zone cells, from $E_{0}$ (no cells) to $E_{4}$, when 10 to 20 sheets of cells exist. Boxes 28 and 29 are used to denote blood (B), pus (P), or spermatozoa (S) in series of degrees according to whether or not their presence obscures a quarter $\left(B_{1}\right)$, half $\left(B_{2}\right)$, threequarters $\left(B_{3}\right)$, or the whole $\left(B_{4}\right)$ of the epithelia element in the smear. This cell scoring is by no means difficult or time-consuming as the technicians become very adept at assessing the average cell content in spite of the widely differing cell content per field. Moreover, this practice keeps the cytotechnicians alert and interested while screenin and provides a greater job satisfaction, especially as they initial the corner of box 22 , where a written report may or may not be recorded. By this method we can rapidly check the detection rate of endocervical cells by one cytotechnician against the laboratory norms. A further check is made by senior or chief technician to note the adequacy of the test and score (when a further initial is placed in the local code box beside box 26), and to assess whether or not the smear needs to be checkscreened. Then that person's initial goes beside that of the screener's in box 22 . The proportion of double-checked reports with two initials amounts on average to $10-15 \%$ of all gvnaecological smears. Such cell scoring helps the pathologist when signing out the report to consider the possible need for a repeat, its time interval, and a suggested further investigation.

I would say that Dr Sworn's rough assessment of $10-15^{\circ}$ of smears lacking endocervical cells is probably a gross underestimate, as many of the published findings quoted have demonstrated that $50 \%$ or more of smears lack these cells-and this is so for those in the child-bearing and sexually active phase of life. ${ }^{12}$ It is obvious that we cannot make the presence or absence of endocervical cells a strict measure of the adequacy of a smear; but such a practice of scoring, when understood by the clinicians and general practitioners served by a laboratory, does help to provide a measure of confidence in a particular test.

\section{O A N Husain}

Division of Pathology, St Stephen's Hospital,
London SW10 9TH

\footnotetext{
${ }^{1}$ Husain, O A N, et al, fournal of Clinical Pathology, ${ }^{2}$ Husain, O A N, Tumori, 1976, 62, 303.
}

SIR,-I was the partner referred to by Dr R E G Sloan (19 May, p 1356). As he stated, we collected reports on all smears over a six month period. Although one technician did request a higher number of repeats than the others, this was far from significant and the numbers involved were not adequate for a firm conclusion to be drawn. As Dr M J Sworn commented (2 June, p 1489), perhaps this technician was the most accurate.

Surely the point of the cervical smear is to exclude malignant or premalignant change, and if it has to be repeated to be certain then this is in the patient's best interest if one accepts the validity of taking the smear in the first instance. Different laboratories obviously have different reporting techniques, and if phrases such as "No malignant cells seen" are used a word with the local pathologist is needed to decide exactly what is meant. The interpretation of technicians and cytologists varies as much as, if not more than, the accuracy of the clinician taking the smear; and it is my impression that the fixing of the smear and the shelf life of the fixative (quoted as indefinite) is more significant than either of the previously mentioned factors.

It seems to be everybody's experience that the smears you are sure are inadequate are reported as normal, and the ones you think are certain to be all right show no endocervical cells.

Cheltenham, Glos GL53 0BA

ROBIN R HARROD

\section{Pressure on tracheal mucosa from cuffed} tubes

SIR,-The use of a low-pressure high-volume cuff (5 May, $p$ 1173) on endotracheal and tracheostomy tubes would appear to offer several theoretical advantages, particularly in the long term $^{12}$; but I have reviewed the experience of our unit using the traditional Portex low-volume, high-pressure cuff in over 1000 consecutive cases of endotracheal intubation and failed to find any cases of tracheal damage or stenosis. My experience of the newer, "floppy" cuff is that the endotracheal tube is difficult to insert via the nose (our usual method for long-term intubation) without bursting the cuff; it sometimes has been difficult to deflate and remove; and the point at which an airtight seal is achieved is as difficult to determine as with the traditional cuff.

It is probably of equal importance to use the correct size of endotracheal tube so that cuff overinflation does not occur, that careful inflation with the minimum volume of air ensures an airtight seal, and that the cuff then remains continuously inflated until it is changed or removed.

Intensive Care Unit,

D W RYAN

Newcastle General Hospital

Newcastle upon Tyne NE4 6BE

1 Cooper, J D, and Grillo, H C, Annals of Surgery, 1969

${ }^{2}$ Crawley, B E, and Cross, D E, Anaesthesia, 1975, 30, 4

\section{Indications for electric convulsion} therapy

SIR,-Inability to cry is a recognised feature of so-called endogenous depression. ECT is said to be more effective in endogenous than in reactive or neurotic depression. I was surprised that Drs David Gill and John Lambourn (5 May, p 1169) did not mention inability to cry as a possible indication for ECT, as in a study I carried out at the University of Sheffield this symptom was a better prognostic sign than early waking, loss of weight, or diurnal variation.

A comparison of the therapeutic effects of unilateral, bifrontal, and bitemporal ECT was carried out. ${ }^{1}$ Subjects completed the Wakefield depression inventory ${ }^{2}$ before and after their course of treatment. The length of course 
varied from three to 10 treatments, most subjects receiving from six to eight shocks. As a side-line to the main study I looked at the clinical features which were associated with a good or bad response to ECT.

Subjects unable to cry were significantly more likely to respond well to ECT, whatever the placement, than were those who could cry $(\mathbf{P}<0.05)$, whereas those with early waking, diurnal variation, or weight loss were no more likely to respond well than those without these features. The presence of depressive delusions was associated with a good response where bilateral ECT was administered, but the response to unilateral ECT was inconsistent. Unfortunately the numbers studied were too small for definite conclusions to be drawn.

\section{Elizabeth A Burroughs}

Doncaster

${ }^{1}$ Clyma, E A, unpublished MD dissertation. University

${ }^{2}$ Snaith, R P, et al, Psychological Medicine, 1971, 1, 143.

\section{What the public wants to know}

SIR,-I was recently involved in a Capital Radio Helpline special day. This is a service seeking to provide information to listeners on any topic, and on this particular day was featuring "medicines." After a short interview over the air, people phoned me confidentially for the rest of the day about any problems they had encountered with their medicines. The interview set the scene with such points as side-effects, interactions, compliance, pregnancy, and disposal of old medicines.

I was surprised at the number of people who were worried about the long-term effects of drugs and the possibility of their becoming "addicted," particularly as the drugs most mentioned were minor tranquillisers and analgesics. More disturbing was the fact that many patients had no idea why they should still be having to get repeat prescriptions for these items after several months, if not years. The overwhelming flood of response I received was an indication not only of the interest the subject provoked but also of what appears to be a genuine gap in patient care somewhere along the line.

Callers were generally shy to go back to their GP and not always able to get to the retail chemist. It does seem a shame that there is nobody to give a few minutes' advice or reassurance that could make all the difference between a successful recovery or a worrying course of treatment.

ROSEMARY FAUNCH

Ealing Hospital,
Southall, Middx

\section{“The Dignity of Labour?"}

SIR,-Your reviewer of Ann Cartwright's important new book The Dignity of Labour? A Study of Childbearing and Induction (19 May, p 1343) assumes that "consultants, registrars, general practitioners or medical students" will not wish to read it. If it were true it would certainly be a tragedy for it would imply that the medical profession is uninterested in its own practices and their effect on the attitudes and preferences of their patients.

Happily, there is plenty of evidence that most doctors are sensitive to their patients' feelings. They want to know what mothers feel about such elective procedures as induction, to take but one example. They will find the book an invaluable source of information on the experiences and opinions of the providers and recipients of maternity services.

Unlike your reviewer I feel that the book should be available in every obstetric unit and postgraduate centre. It should provide all those concerned with the care of the mother and child during pregnancy and childbirth considerable food for thought.

\section{MARGOT JEFFERYS}

Social Research Unit,

Bedford College,

London W1N 1DD

Self-injection of veterinary oil-emulsion vaccines

SIR,-When using an oil emulsion vaccine to immunise a flock of chickens, the vaccinator may inadvertently inject some of the vaccine into his own thumb or finger. A number of such incidents have been reported and all cases appear to have exhibited local symptoms only. These symptoms are pain and inflammation at the injection site, sometimes apparently associated with vasospasm in the blood vessels of the finger that has been accidentally injected. Where there has been delay in seeking medical advice, amputation of a phalanx has been necessary in some cases.

Three main factors contribute to this situation. (1) Any adjuvant vaccine will cause some swelling. In a finger, which has little connective tissue, pain and tension will follow. (2) In some cases the vaccinator has injected himself more than once. This may lead to sensitisation and thus increase the severity of the local reaction. (3) The needle will never be either free of protein or sterile. Non-sterile injections into the hand, even with organisms of low virulence, often cause unpleasant pulp infections.

Our advice to vaccinators is that, in the event of such an accident, the vaccine should be expressed if possible and medical attention sought urgently, certainly within six hours, with an explanation of what has occurred. The sequence of the pathological process appears to follow the line described for greasegun injuries, ${ }^{1}$ although the much smaller volume of vaccine inoculated and the lesser force of injection cause less extensive and less horrifying results. Nevertheless, in the light of the physical distension leading to swelling, numbness, and vascular embarrassment, we consider that early exploration is of prime importance, with incision, irrigation, and drainage of the affected area. Prolonged delay of adequate treatment may result in gangrene and the consequent need for amputation.

Glaxo Operations UK Limited,

P B STONES

Liverpool L24 9JD

\section{Marriage matters}

SIR,-Your correspondence occasioned by the leading article (5 May, p 1164) of "Marriage Matters" included a letter by Dr Joan Coombs (2 June, $\mathrm{p}$ 1486), in which she states that referral of patients requiring psychosexual counselling to an outside agency seems "a terribly retrograde step for the medical profession" and suggests that such counselling should be undertaken by the general practitioner entrusted by the patient with the problem.

No doubt this represents an ideal solution. In the realities of NHS general practice, however, it is rather impractical, except when psychosexual counselling represents a special interest of the particular general practitioner. Another possible solution is the attachment of trained counsellors to individual practices. This solves the problem not only of psychosexual counselling, when the counsellor has had training in sexual dysfunction, but of counselling in the wider sense of the word. In surgery counselling the counsellor becomes a member of the primary care team and the patient's feeling of rejection by his general practitioner is greatly reduced. This was clearly borne out in a recently completed study of nine practices with counsellor attachments in north London.

At present a number of pilot schemes of this kind are operative in various parts of the country, whereby a Marriage Guidance Council attaches a counsellor to an individual general practice team. The bulk of the counsellor's work consists of sexual, marital, and relationship problems and the results recorded so far are very encouraging.

$S$ W WAYDENFELD

London NW5

\section{Obsessionalism and response to lithium}

SIR,-We were interested to read (27 January, p 230) that Drs R J Kerry and J E Orme found psychiatric patients with positive responses to prophylactic lithium treatment to have psychological profiles more like those of the normal controls than those of other psychiatric patients in the study-with the single exception of a scale measure of obsessionalism, on which the lithium responders and other patients were indistinguishable. We have previously reported that bipolar patients, who tend to show more antidepressant responses to lithium than other depressed patients, have more nearly normal psychological test profiles than do unipolar depressed patients. ${ }^{1}$ We have also recently described a psychological test subscale which, in a replication test, successfully predicted lithium responders. ${ }^{2}$

When we re-examined psychological data from this latter study of 53 patients in regard to the question of possible associations between obsessional features and lithium response, we found that 23 of 31 patients $(74 \%)$ who were responders to lithium had $\mathrm{T}$ scores $\geqslant 70\left(\chi^{2}=7.26, P<0.005\right.$, one-tailed $)$ on the Pt scale of the Minnesota Multiphasic Personality Inventory (MMPI), which had been administered prior to treatment. As the MMPI

Pt scale has been shown to provide an index of obsessive-compulsive behaviour, ${ }^{3}$ elevations on this scale suggest that a significant number of lithium responders in our sample have obsessional features.

In a previous study, House and Martin ${ }^{4}$ reported that 21 of 36 responders to the antidepressant effects of lithium had a high ( $T$ score $\geqslant 70$ ) depression (scale 2 ) and psychasthenia (scale 7) MMPI pattern and five nonresponders had a low ( $T$ score $<70$ ) pattern on scales 2 and 7; Donnelly et al also found a similar trend with a depressed population. ${ }^{2}$ Although this pattern on scales 2 and 7 is most frequently found in studies of hospitalised 